\title{
LAS VIVIENDAS DE USO TURÍSTICO: UN ANÁLISIS DEL CONFLICTO
}

\author{
Paula Miralles Marugán' \\ paula.miralles.marugan@gmail.com \\ Arsenio Villar Lama² \\ arsenio@us.es \\ Universidad de Sevilla \\ Facultad de Turismo y Finanzas \\ Área de estudio: Economía y empresa
}

(Fecha envío: 19/11/16 - Fecha aceptación: 17/12/16)

\section{Resumen}

En los últimos años se viene presenciando un continuo descontento de los agentes turísticos ante la aparición y falta de regulación de empresas de economía colaborativa en el sector. Este trabajo tiene como objetivo investigar de manera cualitativa el conflicto existente entre las plataformas Peer to Peer (P2P) y la oferta reglada en el ámbito del alojamiento en España. Para alcanzar dicho objetivo se ha analizado la normativa internacional y se ha implementado una metodología de análisis del discurso mediante un software específico (Atlas.ti). Se concluye que el sector hotelero busca el descenso de la actividad de las empresas de economía colaborativa al exigir su regulación, y que los usuarios P2P seguirán alojándose en estas viviendas mientras crean que aportan un beneficio económico y/o social en el destino. Asimismo, existen discrepancias sobre cual es el perfil del cliente de esta tipología de alojamiento.

\section{Palabras clave}

economía colaborativa, alojamientos P2P, oferta reglada, normativa, análisis del discurso (Atlas.ti), usuarios P2P

\begin{abstract}
In recent years, a constant dissatisfaction of tourism agents has been latent due to the appearance and lack of regulation of collaborative economy companies in this sector. This project aims to explore qualitatively the existing conflict between the Peer to Peer (P2P) platforms and the regulated offer in the accommodation area. To achieve such purpose, international regulation has been analyzed and a methodology of discourse analysis has been implemented using specific software (Atlas. Ti). It is concluded that the hotel industry seeks the decrease of the collaborative economy activity by requiring its regulation and also, that the P2P users will continue accommodating in these dwellings as long as they think that they provide an economic and/or social benefit in the destination. Additionally, it also exist disagreements about the customer's profile of this type of accommodation.
\end{abstract}

\section{Key-words}

collaborative economy, accommodation P2P, regulated offer, speech analysis (Atlas.ti), P2P users

\section{INTRODUCCIÓN}

En los últimos años la evolución de las nuevas tecnologías y su aplicación en el sector turístico han ido configurando nuevos modelos de negocio de gran éxito. Paralelamente, la sociedad del consumo, la globalización, la sostenibilidad, la crisis mundial y otros acontecimientos han determinado la configuración de distintos perfiles de demanda con nuevas necesidades.

Se presenta un nuevo paradigma turístico, nuevas formas de hacer las cosas, de disfrutar del viaje de forma distinta, pero usando las mismas tipologías de servicios. Las empresas creadas bajo los ideales de la economía

\footnotetext{
${ }^{1}$ Graduada en Turismo por la Universidad Carlos III de Madrid, Máster en Dirección y Planificación del Turismo y doctoranda en Geografía en la Universidad de Sevilla.

2 Licenciado y Doctor en Geografía por la Universidad de Sevilla. Profesor Contratado Doctor Interino en el Departamento de Geografía Física y Análisis Geográfico Regional.
} 
colaborativa que operan en el sector del alojamiento son un fenómeno que ha sufrido un crecimiento exponencial en los últimos años y es uno de los grandes retos a los que se enfrenta actualmente el turismo (Exceltur, 2015).

La expansión de plataformas intermediadoras de alquiler turístico preocupa tanto a empresas y a asociaciones hoteleras como a gerentes e instituciones públicas de los principales destinos turísticos mundiales. El conflicto que se ha generado en los últimos años entre la oferta reglada y no reglada llega a tal punto que se ha convertido en foco de atención de la prensa, que refleja frecuentemente las polémicas del sector.

\section{ESTADO DE LA CUESTION: ECONOMIAS COLABORATIVAS Y TURISMO}

Son diversos los autores que tratan de conceptualizar qué es la Economía Colaborativa (EC), pero aún es difícil encontrar una definición de gran precisión y claridad, corriendo el riesgo de una confusión continua sobre su valor y potencial (Stokes, Clarence, Anderson \& Rinne, 2014). De hecho, son varios los conceptos que se emplean como sinónimos de la misma idea (Cuadro 1).

\begin{tabular}{|c|c|}
\hline Término & Definición \\
\hline \multirow[b]{2}{*}{ Sharing Economy } & $\begin{array}{l}\text { Un sistema socioeconómico para la producción, distribución, comercio y consumo } \\
\text { compartido de bienes y servicios por parte de diferentes personas y organizaciones. }\end{array}$ \\
\hline & $\begin{array}{l}\text { Un modelo económico basado en el intercambio de activos infrautilizados, desde } \\
\text { espacios hasta habilidades y cosas, a cambio de un beneficio monetario o no } \\
\text { monetario. Se ha relacionado con los mercados P2P (Peer-to-Peer), pero también se } \\
\text { encuentran en los modelos B2C (Business-to-Consumer). }\end{array}$ \\
\hline $\begin{array}{l}\text { Collaborative } \\
\text { Economy }\end{array}$ & $\begin{array}{l}\text { Una economía basada en redes distribuidas de individuos y comunidades conectadas } \\
\text { frente a instituciones centralizadas, transformando la forma en que se puede producir, } \\
\text { consumir, financiar y aprender. }\end{array}$ \\
\hline \multirow{3}{*}{$\begin{array}{l}\text { Collaborative } \\
\text { Consumption }\end{array}$} & $\begin{array}{l}\text { Utilizar el exceso de capacidad de las mercancías a través del acceso a la propiedad. } \\
\text { Puede ser Business-to-Consumer (B2C), Business-to-Business (B2B) o Peer-to-Peer } \\
\text { (P2P). }\end{array}$ \\
\hline & $\begin{array}{l}\text { La reinvención de los comportamientos tradicionales del mercado, tales como el } \\
\text { trueque, el alquiler, el comercio y el intercambio, a través de la tecnología, lo que les } \\
\text { permite tener lugar en una escala y en formas nunca antes posibles. Se está } \\
\text { reinventando no sólo lo que consumimos sino la forma en la que lo hacemos. }\end{array}$ \\
\hline & $\begin{array}{l}\text { El consumo colaborativo alude a gente coordinándose para la adquisición y distribución } \\
\text { de un recurso por una tarifa u otra compensación. }\end{array}$ \\
\hline \multirow{3}{*}{$\begin{array}{l}\text { Peer-to-Peer } \\
\text { (P2P) } \\
\text { o Peer } \\
\text { Economy }\end{array}$} & $\begin{array}{l}\text { Se centra en la derivación de los intermediarios como los bancos y hoteles, y en el } \\
\text { intercambio entre los individuos dentro de la sociedad civil. }\end{array}$ \\
\hline & $\begin{array}{l}\text { Se ha aplicado a las organizaciones en torno al modelo de negocio "peer-to-peer" ("de } \\
\text { igual a igual"), en el que la gente utiliza plataformas para alquilar, vender, prestar o } \\
\text { compartir cosas con los demás sin la participación de tiendas, bancos o agencias. }\end{array}$ \\
\hline & $\begin{array}{l}\text { Mercados "persona-a-persona" ("de igual a igual") que facilitan el intercambio y el } \\
\text { comercio directo de los activos basado en la confianza entre iguales. }\end{array}$ \\
\hline The Mesh & $\begin{array}{l}\text { Las relaciones entre la tecnología y el acceso a la interacción de individuos en nuevas } \\
\text { formas gracias a estas tecnologías. Este término se centra en la interconexión de las } \\
\text { redes sociales entre personas. }\end{array}$ \\
\hline
\end{tabular}

\section{Cuadro 1: Aproximaciones conceptuales}

Fuente: Elaboración propia a partir de (Stokes, Clarence, Anderson \& Rinne, 2014), (Allen \& Berg, 2014), (Belk, 2014) y (Botsman, 2013)

Siguiendo los conceptos y definiciones aportados por Botsman (2013) se puede entender que la EC se basa en cuatro pilares de actividad dependiendo de su propósito, esto es, la producción (1), el consumo (2), las finanzas (3) y el aprendizaje colaborativo (4):

1) La Producción Colaborativa se refiere a grupos o redes de individuos que colaboran para diseñar, producir o distribuir bienes.

2) El Consumo Colaborativo alude al acceso a bienes o servicios a través del trueque, el alquiler, el préstamo, el comercio, el intercambio y la reventa. Se obtiene una máxima utilización de los bienes a 
través de modelos de redistribución y acceso compartido. Este pilar se fundamenta en 3 sistemas para desarrollarse: el sistema de servicios del producto (se paga por el uso del producto sin adquirir su propiedad), los mercados de redistribución (reventa o redistribución de las cosas infrautilizadas en origen) y los estilos de vida colaborativo (gente que quiere compartir e intercambiar activos intangibles como el tiempo, las habilidades, el dinero y el espacio). Asimismo, en el consumo colaborativo se pueden dar tres modelos de transacciones para estos bienes y servicios (Stokes et al., 2013):

a) Business-to-Consumer (B2C): La interacción entre los consumidores y las empresas que poseen o directamente administran su inventario.

b) Business-to-Business (B2B): La interacción entre una empresa y otras empresas que poseen o directamente gestionan su inventario.

a) Peer-to-Peer (P2P): La interacción entre dos o más personas para el comercio o el intercambio de un bien o servicio facilitado y apoyado por una empresa, organización o plataforma que no está directamente involucrado en la transacción.

3) Las Finanzas Colaborativas se relacionan con servicios de financiación, préstamos e inversiones que se ofrecen fuera de las instituciones financieras tradicionales, como por ejemplo el Crowfunding.

4) El Aprendizaje Colectivo hace referencia a experiencias accesibles para cualquier persona y donde los individuos comparten recursos y conocimientos para aprender juntos. Uno de los ejemplos más conocidos de este tipo de actividad colaborativa es la web Wikipedia.

Siguiendo a Botsman (2013), todos estos términos tienen en común tres temas principales:

- La distribución del poder, pues en todos los sectores, el poder se está descentralizando. De las grandes instituciones, el poder se está distribuyendo entre las redes de individuos y comunidades, cambiando en quién confiamos y cómo accedemos a los bienes y servicios. Desde el punto de vista empresarial, lo que se está creando es lo que se conoce como una "desintermediación", función proporcionada por plataformas webs que proveen eficiencia y confianza. Asimismo, otro gran poder reside en el cambio social que se está experimentando recientemente, el paso de una de una sociedad de consumidores pasivos a creadores activos y conectados.

- Controladores disruptivos. Toda EC tienen en común estos cuatro factores clave: la innovación tecnológica (redes sociales, pagos online, sistemas de identidad en línea...), el cambio de valores (sociedad conectada que reconsidera el significado de la propiedad y el intercambio), la nueva concepción de la riqueza (medir el "crecimiento" de una manera más significativa) y las presiones ambientales (la necesidad de hacer un mejor uso de los recursos finitos).

- La utilización de activos de manera innovadora y eficiente. Las nuevas tecnologías permiten desbloquear lo que se denomina "idling capacity" o esa capacidad de improductividad, de falta de aprovechamiento e infrautilización de un bien (por ejemplo, asientos vacíos en los coches, espacios de oficina desocupados, habilidades no utilizadas, etc.) Las redes sociales o tecnologías móviles basadas en la localización permiten la conectividad de personas de manera cada vez más eficiente y segura para el intercambio de bienes infrautilizados. Se trata de un recurso apenas explotado y con grandes beneficios: reducción de residuos, disminución de costes, valores de comunidad, espíritu empresarial y beneficio económico.

Otros autores (Allen \& Berg, 2014; De la Calle \& De la Calle, 2013) identifican los temas anteriores que expone Botsman (2013) como beneficios de los mercados de las ECs frente a los mercados tradicionales: un mayor uso sostenible de los recursos infrautilizados, una mejor satisfacción de las necesidades y deseos de los consumidores, y una reducción de los precios de los bienes a través de la descentralización.

El sector turístico tradicionalmente ha estado marcado por una relación de cliente-empresa basado en el modelo B2C (Business-to-Consumer) donde el cliente adquiría productos y servicios directamente con las empresas turísticas (Botsman, 2013; Botsman \& Rogers, 2011; Stokes, et al., 2014). Con el avance de las nuevas tecnologías y expansión de internet a los dispositivos móviles, se abrió camino a la aparición de nuevas empresas operativas en el sector turístico y con presencia exclusiva en la red. Entre ellas, destacaron inicialmente las webs de búsqueda de ofertas.

Pero las oportunidades que ofrecen las nuevas tecnologías (redes sociales, dispositivos móviles, sistemas de pago online, etc.) unidas a los cambios sociales (mayor preocupación por la sostenibilidad, sentimiento de comunidad, etc.) y la crisis económica ha fomentado la aparición de nuevos "jugadores" en el sector turístico. Estos son capaces de hacer frente y de satisfacer las nuevas necesidades del turista más concienciado, el turista que ha reevaluado sus valores y hábitos de consumo (De la Calle \& De la Calle, 2013).

Sin embargo, ha sido el rápido desarrollo de la tecnología el principal impulsor de las economías colaborativas (ECs, en adelante). El factor determinante es que estas plataformas P2P, ya sean alojamiento, transporte $u$ otro sector, disponen de una versión web y de aplicación móvil. Los dispositivos móviles se han convertido en los nuevos puntos de venta (Olson \& Kemp, 2015). Los turistas suelen viajar sin sus dispositivos pesados, mientras 
que los móviles les acompañan en todo momento, convirtiéndose éstos en la puerta de entrada al mercado online. Con un Smartphone y acceso a internet el turista dispone de información sobre dónde ir, qué hacer, dónde alojarse, qué comer o cómo moverse en el destino. Tienen al alcance de la mano todo lo que necesitan saber para disfrutar del destino y, por tanto, aumenta la autosuficiencia del turista.

Según diversos autores, la EC es percibida como una oferta mejor valorada y con un menor coste (Tussyadiah, 2015: Botsman \& Rogers, 2011; Gansky, 2010; Lamberton \& Rose, 2012; Sacks, 2011), un fenómeno creado por individuos en busca de precios más bajos y de generar beneficios (Olson \& Kemp, 2015).

Con la aparición de esta nueva tendencia de consumo en el turismo se presenta un nuevo paradigma en el sector, una nueva forma de disfrute del viaje, una ampliación de la zona de confianza por la cual el turista desarrolla cada una de las etapas de su viaje.

Tradicionalmente, previa a la aparición de las ECs en el turismo, el turista se ha movido durante sus vacaciones en un marco de confianza generado por la numerosa oferta reglada tanto en el alojamiento (hotel, camping, etc.) como en el proceso del viaje (avión, vehículo propio, tren, etc.) y en el uso de servicios turísticos en el destino (guías y transporte urbano). Se puede decir que esta zona de confort del turista es estática ya que éste se mueve en ámbitos regulados por diferentes normativas y en los cuales es conocedor de sus opciones en cuanto a la oferta y los derechos asociados a su uso. Sin embargo, con la llegada de las economías colaborativas al sector turístico, este espacio en el que el turista se desenvuelve y se siente cómodo evoluciona, se amplia, se genera una nueva zona de confianza más flexible y asimétrica (Figura1).

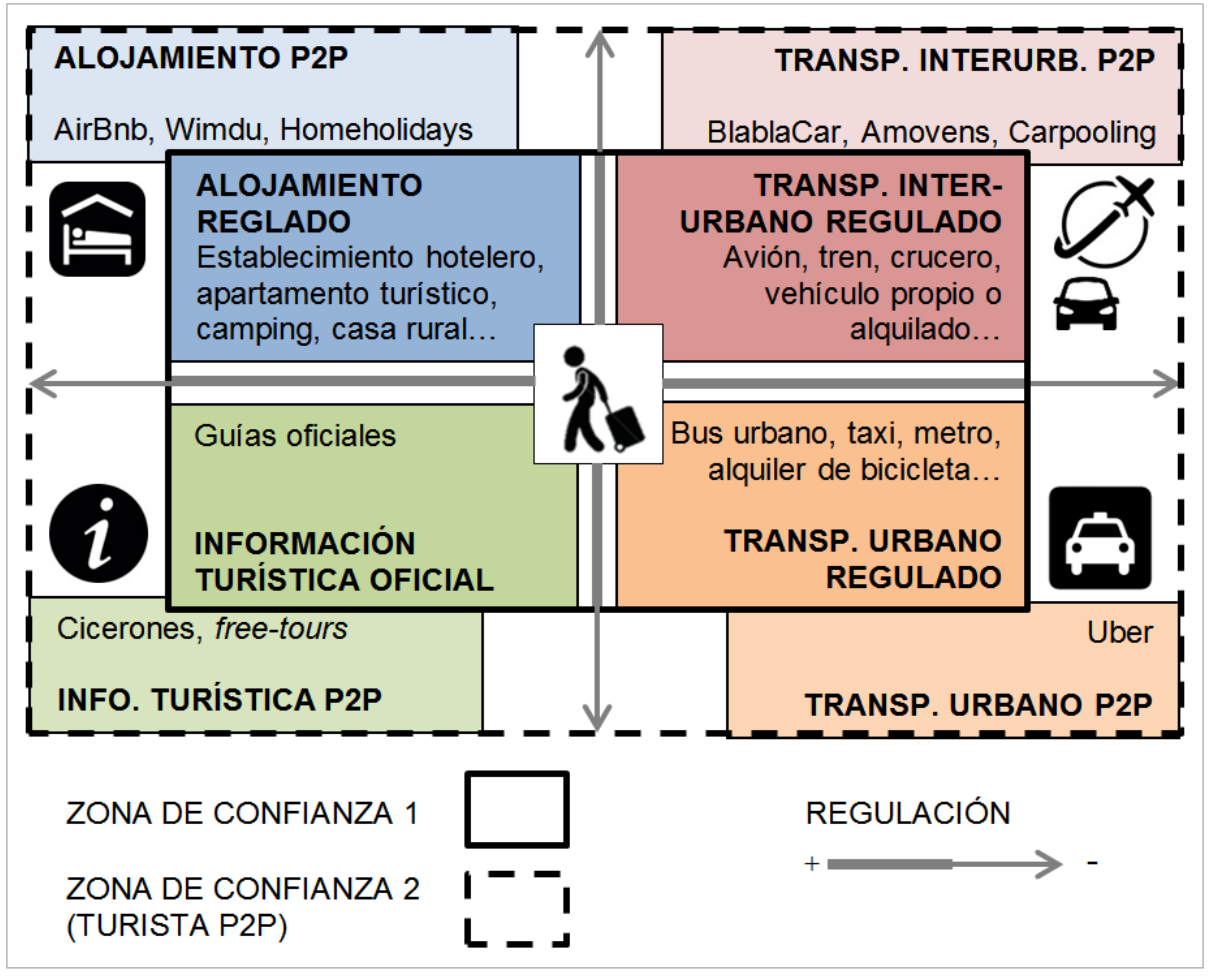

Figura 1: Zonas de confianza del turista Fuente: Elaboración propia

Debido a la falta de regulación de las ECs en los diferentes subsectores turísticos (alojamiento, movilidad urbana e interurbana y servicios de guía e información) la presencia del turista en estos ámbitos no es la misma. Dependiendo de las características de cada oferta, el usuario de ECs está más o menos dispuesto a sustituir la oferta reglada por la que proporcionan las plataformas P2P:

- El sector del alojamiento es hasta el momento el que más terreno está ganando en esta nueva realidad turística, hecho que se demuestra con el número de establecimientos disponibles en una sola plataforma, por ejemplo, Airbnb cuenta con más de 8.500 .000 de establecimientos en el mundo (CEHAT, 2013) y cerca de 85.000 viviendas en España en 2015 (Exceltur, 2015).

- En el sector del transporte (véase Cohen \& Kietzmann, 2014: Freese \& Schönberg, 2014) la falta de regulación de estos ámbitos, sobre todo relacionado con la seguridad, es un motivo de desconfianza para su uso. A pesar de ello, plataformas como "Blablacar" (movilidad interurbana) está siendo en muchas 
ocasiones un sustitutivo de la oferta tradicional (autobuses de línea, tren, etc.). Actualmente, Blablacar cuenta con 20 millones de usuarios de los cuales 2,5 millones están registrados en España ${ }^{3}$.

- Los servicios de información turística que ofrecen los guías en las empresas P2P, parecen ser una opción que se va expandiendo con la aparición de nuevos actores. Aun existiendo conflicto entre ambas modalidades (oficial vs. no oficial), los turistas contratan los servicios de visitas guiadas con profesionales no acreditados para realizar rutas y visitar monumentos en los que no es obligatorio el servicio del guía oficial, el cual se limita a una serie de espacios de propiedad pública o privada (y cuya actividad está regulada por la ley). En los últimos años se han multiplicado las rutas turísticas gratuitas a cambio de propinas donde el turista es quién decide lo que paga a modo de valoración del servicio prestado ${ }^{4}$.

Siguiendo el esquema planteado, las zonas de confianza no son excluyentes. Generalmente un turista se mueve hoy entre la oferta tradicional y los nuevos servicios P2P. Esta nueva orla de posibilidades en el alojamiento, el transporte o las visitas está siendo objeto de un controvertido debate, que se refleja en la prensa, publicaciones especializadas o en reuniones entre profesionales de cada sector. Abordado el fenómeno como competencia desleal y perjudicial para los destinos turísticos; y teniendo en cuenta la rápida proliferación de plataformas P2P y la dimensión que ha adquirido en el sector, este trabajo pretende abordar y arrojar luz sobre el asunto.

\section{OBJETIVOS}

El objetivo principal del presente trabajo es investigar y analizar de manera cualitativa el conflicto existente entre las economías colaborativas del sector del alojamiento y la oferta reglada en España. Este objetivo general se concreta en los siguientes objetivos específicos:

- Contextualizar las economías colaborativas y su desarrollo en el sector turístico (transporte, alojamiento y guías locales).

- Analizar las normativas nacionales e internacionales en relación con estas nuevas fórmulas de alojamiento.

- Indagar en la opinión de los agentes implicados en el conflicto mediante el análisis del discurso con la herramienta de investigación cualitativa Atlas.ti.

- Determinar la valoración de las economías colaborativas en el sector del alojamiento por parte de los distintos agentes sociales implicados en la actividad.

\section{FUENTES Y METODOLOGÍA}

Para alcanzar los objetivos de este proyecto se han de llevar a cabo una serie ordenada de acciones (Figura 2). Por un lado, se recaba y analiza información secundaria relacionada con las economías colaborativas en investigaciones, estudios, tesis, informes y publicaciones especializadas (metodología general de la investigación). Por otra parte, como método más específico, se plantea un análisis del discurso que permita sintetizar, ordenar, confrontar y analizar toda la información recabada, generando, al mismo tiempo, nuevas ideas y planteamientos.

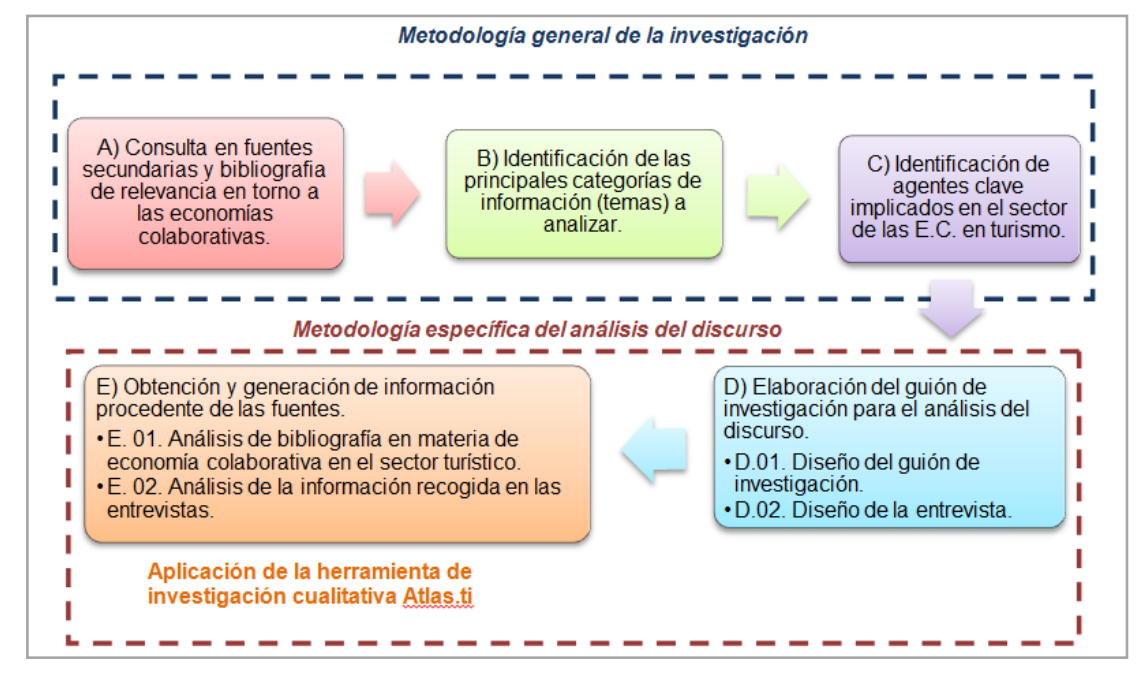

Figura 2: Metodología general y específica Fuente: Elaboración propia

\footnotetext{
${ }^{3}$ Véase: http://economia.elpais.com/economia/2015/10/15/actualidad/1444928962 161604.html

${ }^{4}$ Consúltese: $\underline{\text { http://www.hosteltur.com/113479 polemicos-free-tours-se-extienden-toda-espana.html }}$
} 
La naturaleza del fenómeno estudiado, por su carácter emergente y por su condición de alegal, conduce a una investigación cualitativa y al empleo de técnicas propias de este tipo de pesquisas. Se buscan motivaciones, actitudes, confrontaciones y problemáticas de diversos colectivos vinculados con la temática.

La consulta y en análisis bibliográfico permite, en primera instancia, seleccionar los principales temas y los actores implicados. En segundo lugar, se diseña el guión de la investigación y de las entrevistas, fuente primaria, cuyos resultados serán volcados, junto a la bibliografía, en un software específico de análisis del discurso (Programa Atlas.ti)

Para el análisis del discurso en el citado programa es necesario llevar a cabo una serie de tareas ordenadas que permita la obtención de información deseada. Tras el volcado de documentación bibliográfica, se procede a la elaboración de códigos que permita ordenar la información según temas para su codificación y extracción de discursos asociados (citas/quotes) a cada código. A continuación se puede observar una muestra del resultado que se obtendría en Atlas.ti tras la codificación en la que se extrae sería el discurso y las citas asociadas a ese texto (Figuras 3 y 4 ).

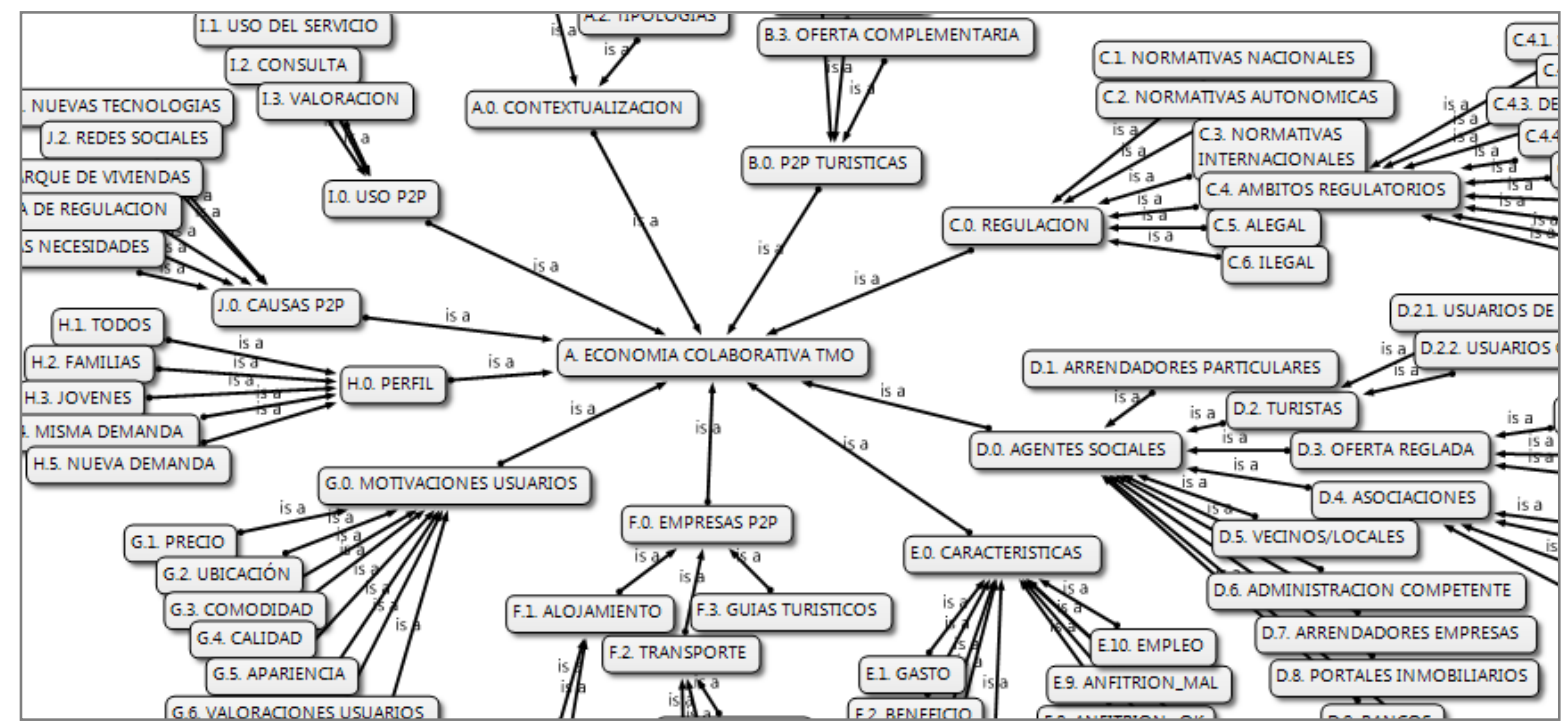

Figura 3: Textos y códigos asociados

Fuente: Extraído del proceso de análisis (Atlas.ti)

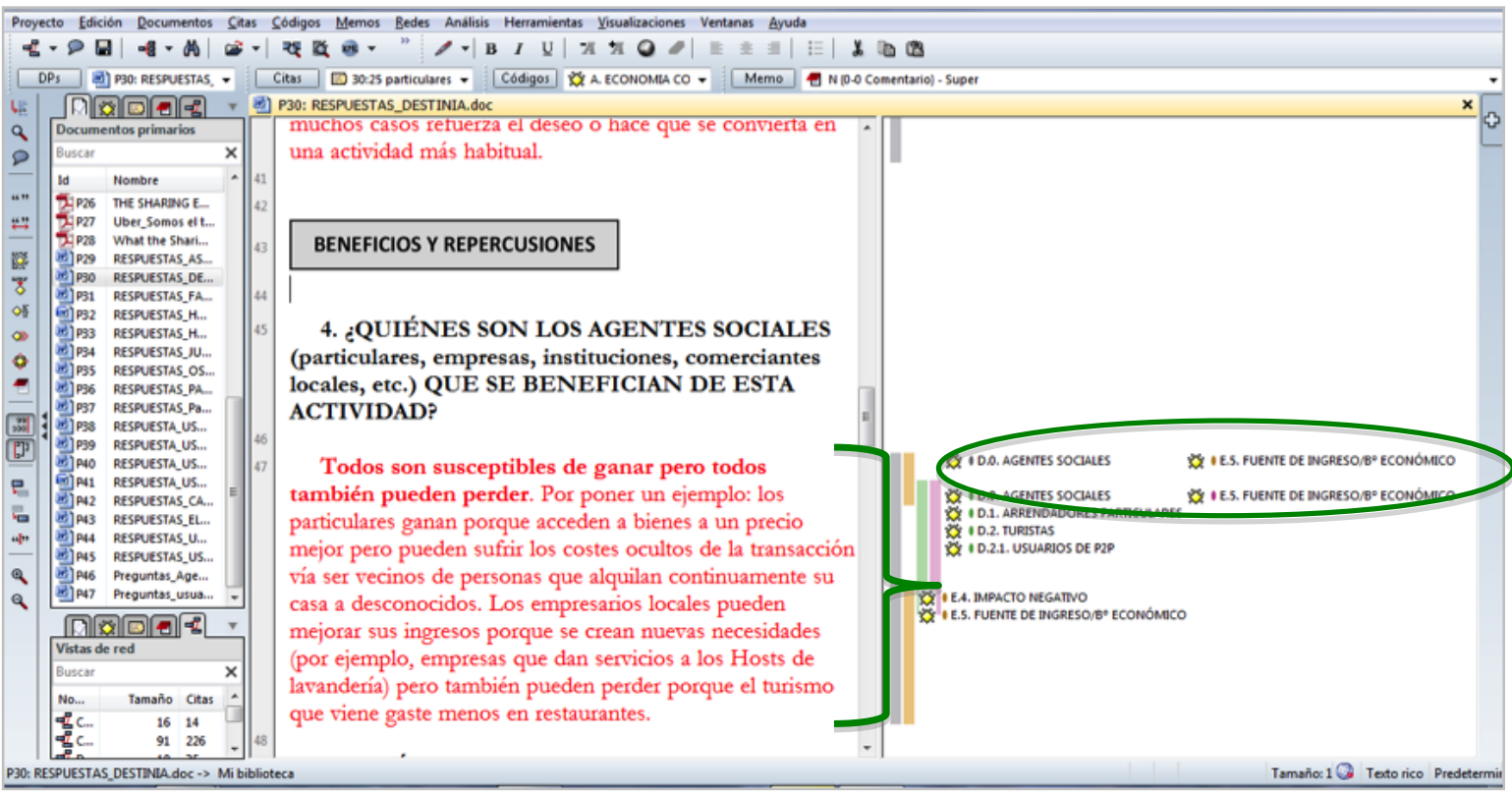

Figura 4: Extracto de la Red de códigos

Fuente: Extraído del proceso de análisis (Atlas.ti) 


\section{RESULTADOS}

\subsection{Análisis normativo}

Desde hace años, los profesionales del sector turístico en España, tanto agentes privados como públicos, son conscientes de que pese a existir normativas autonómicas en materia turística, el contenido y su regulación no es homogénea en todas las regiones. Según el análisis normativo realizado por Tourism \& Law (Exceltur, 2015) las recientes regulaciones ( 7 hasta el momento) de las viviendas de alquiler para uso turístico sufren de la misma falta de homogeneidad que las normativas turísticas de la oferta reglada existentes en los distintos territorios autonómicos.

\begin{tabular}{|c|c|c|c|c|c|c|}
\hline TEMÁTICA/ÁMBITO & Aragón & Baleares & Canarias & Cantabria & Cataluña & Madrid \\
\hline $\begin{array}{l}\text { Autorización/registro } \\
\text { de la actividad }\end{array}$ & $\begin{array}{l}\text { Sí, mediante } \\
\text { declaración } \\
\text { responsable }\end{array}$ & $\begin{array}{l}\text { Sí, mediante } \\
\text { declaración } \\
\text { responsable }\end{array}$ & $\begin{array}{l}\text { Sí, mediante } \\
\text { declaración } \\
\text { responsable }\end{array}$ & $\begin{array}{l}\text { Sí, mediante } \\
\text { declaración } \\
\text { responsable }\end{array}$ & Sí & $\begin{array}{l}\text { Sí, mediante } \\
\text { declaración } \\
\text { responsable }\end{array}$ \\
\hline Dotaciones mínimas & $\begin{array}{l}\text { Teléfono 24h., } \\
\text { precio } \\
\text { expuesto y } \\
\text { placa distintiva }\end{array}$ & $\begin{array}{l}\text { Teléfono 24h. y } \\
\text { placa distintiva }\end{array}$ & $\begin{array}{l}\text { Teléfono 8-20h., } \\
\text { precio expuesto } \\
\text { y placa distintiva }\end{array}$ & $\begin{array}{l}\text { Teléfono 24h., } \\
\text { precio } \\
\text { expuesto y } \\
\text { placa } \\
\text { distintiva }\end{array}$ & $\begin{array}{l}\text { Teléfono } \\
24 \mathrm{~h} .\end{array}$ & $\begin{array}{l}\text { Teléfono } 24 \mathrm{~h} ., \\
\text { precio } \\
\text { expuesto y } \\
\text { placa distintiva }\end{array}$ \\
\hline $\begin{array}{l}\text { Periodo o } \\
\text { habitualidad del } \\
\text { arrendamiento }\end{array}$ & No establece & No establece & $\begin{array}{l}2 \text { o más veces } \\
\text { un mismo año o } \\
\text { todos los años } \\
\text { de forma habitual }\end{array}$ & $\begin{array}{l}\text { Se debe } \\
\text { comercializar } \\
\text { de forma } \\
\text { profesional } \\
\text { y/o habitual }\end{array}$ & $\begin{array}{l}\text { Sí, a } \\
\text { partir de } \\
2 \text { veces } \\
\text { al año }\end{array}$ & $\begin{array}{l}\text { Mínima } \\
\text { estancia de } 5 \\
\text { días }\end{array}$ \\
\hline Alquiler de estancias & No & No & No & No & No & No \\
\hline $\begin{array}{l}\text { Hojas de } \\
\text { reclamaciones }\end{array}$ & $\begin{array}{l}\text { No } \\
\text { expresamente }\end{array}$ & Sí & Sí & Sí & Sí & $\begin{array}{l}\text { No } \\
\text { expresamente }\end{array}$ \\
\hline Ficha de policía & $\begin{array}{l}\text { No } \\
\text { expresamente }\end{array}$ & $\begin{array}{l}\text { No } \\
\text { expresamente }\end{array}$ & Sí & Sí & Sí & $\begin{array}{l}\text { No } \\
\text { expresamente }\end{array}$ \\
\hline Otros & & $\begin{array}{l}\text { Prohibición por } \\
\text { tipologías: } \\
\text { Excluidos los } \\
\text { pisos en } \\
\text { propiedad } \\
\text { horizontal }\end{array}$ & $\begin{array}{l}\text { Prohibición por } \\
\text { zonificación: } \\
\text { Excluidas zonas } \\
\text { turísticas, } \\
\text { urbanizaciones } \\
\text { turísticas o } \\
\text { mixtas }\end{array}$ & & & \\
\hline
\end{tabular}

Cuadro 2: Síntesis de la normativa autonómica (excl. Andalucía)

Fuente: Elaboración propia a partir de Exceltur (2015)

La Ley 29/1994 de Arrendamientos Urbanos (LAU) ha servido a los propietarios de viviendas particulares como sustento legal para dedicarlas a la actividad turística mediante la figura de "arrendamientos por temporada" (Román, 2014). La Ley de medidas de flexibilización y fomento del mercado de alquiler de viviendas (Ley 4/2013) modifica la LAU excluyendo las viviendas de alquiler para uso turístico, tal y como puede observarse en el renovado artículo 5: "Se excluye del ámbito de aplicación la cesión temporal de uso de la totalidad de una vivienda amueblada y equipada en condiciones de uso inmediato, comercializada o promocionada en canales de oferta turística y realizada con finalidad lucrativa, cuando esté sometida a un régimen específico, derivando de su normativa sectorial". Ante este vacío legal y el crecimiento exponencial de esta fórmula alojativa, diversas Comunidades Autónomas han elaborado normativas específicas: Baleares (2011), Cataluña (2012), Cantabria, Madrid (2014), Aragón, Canarias (2015) y Andalucía (2016).

Hasta el momento, de los 24 ámbitos normativos ${ }^{5}$ de obligado cumplimiento para la oferta reglada, solo 7 de ellos se contemplan parcialmente ${ }^{6}$ en las nuevas normativas sobre oferta no regulada: registro turístico, protección de los derechos de consumidores y usuarios, existencia de hojas de reclamaciones, ámbito laboral y prevención de riesgos laborales, orden público y seguridad, fiscalidad y tributación, responsabilidad solidaria. Se puede observar como en las 6 comunidades autónomas incluidas en el Cuadro 2 solo se coincide en la regulación del tipo de alquiler (únicamente se permite alquilar la vivienda al completo, no por habitaciones), en la obligación de inscribir el alojamiento en el registro turístico correspondiente (principalmente como medio de

\footnotetext{
${ }^{5}$ Los ámbitos normativos a los que la oferta reglada se ve obligada a cumplir en territorio español son: Registro turístico, Protección de los derechos de consumidores y usuarios, Existencia de hojas de reclamación, Ámbito laboral y prevención de riesgos laborales, Orden público y seguridad, Fiscalidad y tributación, Responsabilidad solidaria, Remuneración de la propiedad intelectual, Protección de datos personales, Comercio electrónico, Higiene alimentaria y medidas sanitarias, Espectáculos públicos, Higiene hídrica, Servicios de limpieza, Tamaños mínimos y calidades, Instalaciones eléctricas, Instalaciones térmicas, Calderas y aparatos a presión, Instalaciones frigoríficas, Prevención contra incendios, Accesibilidad y supresión de barreras arquitectónicas, Ascensores y aparatos elevadores, Medio ambiente y eficiencia energética, y Piscinas. ${ }^{6}$ Con "parcialmente" se quiere decir que en una normativa autonómica se recoge alguno de los ámbitos normativos. (Exceltur, 2015: 65)
} 
control del número de establecimientos de esta tipología y a modo de repercutir los correspondientes impuestos y sanciones) y, finalmente, la prestación obligatoria de un servicio de atención telefónica al cliente 24 horas.

En Andalucía, mediante el Decreto 28/2016, se siguen en líneas generales las mismas pautas que en el resto de normas autonómicas (registro de la actividad, dotaciones mínimas, establecimiento de un periodo máximo, hojas de reclamaciones...) con algunas particularidades como, por ejemplo, la posibilidad de alquilar habitaciones (siempre que el propietario resida en la vivienda).

Existen otros aspectos regulatorios relevantes como el tiempo de arrendamiento permitido (habitualidad) o la zonificación de la actividad (como mecanismo de protección de la comunidad de vecinos y residentes) que son objeto de regulación tanto a nivel nacional como internacional. Sin embargo, las bases de estos ámbitos normativos son dispares en cada destino (Cuadros 3 y 4 ).

\begin{tabular}{|c|c|c|c|c|}
\hline TEMÁTICA/ÁMBITO & $\begin{array}{l}\text { San Francisco } \\
\text { (EEUU) }\end{array}$ & $\begin{array}{l}\text { Nueva York } \\
\text { (EEUU) }\end{array}$ & $\begin{array}{l}\text { Chicago } \\
\text { (EEUU) }\end{array}$ & $\begin{array}{l}\text { Quebec } \\
\text { (Canadá) }\end{array}$ \\
\hline $\begin{array}{l}\text { Autorización/registro de la } \\
\text { actividad }\end{array}$ & $\begin{array}{l}\text { Coste de } 50 \$ \text { cada } 2 \\
\text { años }\end{array}$ & & $\begin{array}{l}\text { Obligatorio. } \\
\text { Mecanismo para } \\
\text { cuantificar actividad } \\
\text { y orientar políticas } \\
\text { turísticas. }\end{array}$ & $\begin{array}{l}\text { Documentación, } \\
\text { pago de tasas, } \\
\text { expedición del } \\
\text { certificado. }\end{array}$ \\
\hline Dotaciones mínimas & & & $\begin{array}{l}\text { Obligatoriedad de } \\
\text { ofrecer jabón, toallas } \\
\text { y ropa de cama. } \\
\text { Visibilidad del } \\
\text { número de licencia y } \\
\text { plano evacuación }\end{array}$ & $\begin{array}{l}\text { Sistema de cálculo } \\
\text { de media ponderada } \\
\text { según ítems } \\
\text { establecidos que } \\
\text { establecerá la } \\
\text { categoría. }\end{array}$ \\
\hline $\begin{array}{l}\text { Periodo o habitualidad del } \\
\text { arrendamiento }\end{array}$ & $\begin{array}{l}\text { Mín. } 32 \text { días y máx. } \\
90 \text { días al año }\end{array}$ & $\begin{array}{l}\text { Mín. } 30 \text { días } \\
\text { consecutivos }\end{array}$ & & $\begin{array}{l}\text { Mín. } 6 \text { horas y máx. } \\
31 \text { días continuados. }\end{array}$ \\
\hline $\begin{array}{l}\text { Protección de la } \\
\text { población local o } \\
\text { comunidad de vecinos }\end{array}$ & & $\begin{array}{l}\text { Zonificación por tipo de } \\
\text { vivienda: "Clase A" } \\
\text { prohibida actividad. } \\
\text { "Clase B" permitido. } \\
\text { Autorización comunidad } \\
\text { de vecinos si no hay } \\
\text { prohibición en Estatutos }\end{array}$ & & \\
\hline Seguridad/Inspecciones & & & $\begin{array}{l}\text { Inspección del Dep. } \\
\text { Buildings Inspection } \\
\text { y Dep. Zoning }\end{array}$ & $\begin{array}{l}\text { Seguro de } \\
\text { responsabilidad civil } \\
\text { obligatorio }\end{array}$ \\
\hline Sanciones & $\begin{array}{l}\text { Sistema de } \\
\text { sanciones para quien } \\
\text { no cumpla con las } \\
\text { disposiciones de la } \\
\text { Ley "Airbnb" }\end{array}$ & $\begin{array}{l}\text { Multas por } \\
\text { incumplimiento de la } \\
\text { normativa }\end{array}$ & & \\
\hline Otros & $\begin{array}{l}\text { Medida de control: } \\
\text { Obligatoriedad de las } \\
\text { plataformas P2P de } \\
\text { informar sobre uso } \\
\text { real de las viviendas } \\
\text { anunciantes }\end{array}$ & & $\begin{array}{l}\text { Pago de tasas al } \\
\text { Departamento de } \\
\text { Asuntos de } \\
\text { Negocios y } \\
\text { Protección del } \\
\text { Consumidor. } \\
\text { Profesional }>6 \text { hab. }\end{array}$ & $\begin{array}{l}\text { Impuestos } \\
\text { específicos sobre la } \\
\text { actividad }\end{array}$ \\
\hline
\end{tabular}

Cuadro 3: Síntesis de la normativa internacional: Norteamérica Fuente: Elaboración propia a partir de Exceltur (2015)

Las líneas de regulación de cada ámbito son desiguales, principalmente, porque éstas se ajustan a las características de cada territorio (y/o destino turístico) tienen como fin controlar y reducir las externalidades y efectos negativos de la actividad de alojamiento P2P.

Entre los ámbitos regulatorios más comunes en todas las normativas internacionales y, por tanto, aspectos que mayor preocupación provoca en los legisladores y agentes de la oferta reglada, se encuentran el tiempo de arrendamiento, el registro de la actividad y la seguridad. Aunque son recurrentes en la mayoría de normativas, el contenido de cada uno es distinto.

Desde 2015 se confirma el interés por parte de las administraciones en la regulación de este fenómeno. La Comisión Europea, en su búsqueda de unas reglas comunes para la economía colaborativa, prepara un documento de referencia para la futurible aparición de numerosas normativas al respecto ${ }^{7}$. Por su parte, la Comisión Nacional del Mercado de Valores está elaborando un informe sobre estos nuevos modelos de

\footnotetext{
${ }^{7}$ La Unión Europea ha publicado numerosos informes y estudios al respecto.

Véase: http://www.europarl.europa.eu/RegData/etudes/STUD/2015/563411/IPOL STU(2015)563411 EN.pdf
} 
prestación de servicios y ha abierto un proceso de participación pública ${ }^{8}$. Finalmente, la Junta de Andalucía ha aprobado en febrero de 2016 su Decreto sobre viviendas con fines turísticos ${ }^{9}$.

\begin{tabular}{|c|c|c|c|c|}
\hline TEMÁTICA/ÁMBITO & $\begin{array}{l}\text { Paris } \\
\text { (Francia) }\end{array}$ & $\begin{array}{l}\text { Región de Lazio } \\
\text { (Italia) }\end{array}$ & $\begin{array}{l}\text { Región de Flandes } \\
\text { (Bélgica) }\end{array}$ & $\begin{array}{l}\text { Región de Tirol } \\
\text { (Austria) }\end{array}$ \\
\hline $\begin{array}{l}\text { Autorización/registro de } \\
\text { la actividad }\end{array}$ & $\begin{array}{l}\text { Si el alquiler es } \\
\text { superior a dos } \\
\text { semanas al año es } \\
\text { necesaria autorización } \\
\text { de la actividad. }\end{array}$ & $\begin{array}{l}\text { Autorización concedida } \\
\text { por la Agencia de Turismo } \\
\text { según clasificación del } \\
\text { alojamiento determinada } \\
\text { por las dotaciones } \\
\text { mínimas. Presentación de } \\
\text { gran cantidad de } \\
\text { documentación. }\end{array}$ & $\begin{array}{l}\text { No hay obligación } \\
\text { pero hay que } \\
\text { comunicar el } \\
\text { desarrollo de la } \\
\text { actividad y aportar } \\
\text { documentación } \\
\text { específica. }\end{array}$ & $\begin{array}{l}\text { Necesaria } \\
\text { autorización }\end{array}$ \\
\hline Dotaciones mínimas & & $\begin{array}{l}\text { Normativa con } \\
\text { especificaciones muy } \\
\text { precisas. Se prohíben las } \\
\text { literas. Obligatorio prestar } \\
\text { servicio de desayuno. }\end{array}$ & $\begin{array}{l}\text { Listado de } \\
\text { especificaciones de } \\
\text { obligado } \\
\text { cumplimiento, entre } \\
\text { ellas: gestor } \\
\text { establecimiento } \\
\text { disponible en horario } \\
\text { de oficina }\end{array}$ & \\
\hline $\begin{array}{l}\text { Periodo o habitualidad } \\
\text { del arrendamiento }\end{array}$ & $\begin{array}{l}\text { Mín. } 7 \text { días } \\
\text { consecutivos (para } \\
\text { toda Francia) }\end{array}$ & $\begin{array}{l}\text { Entre } 3 \text { y } 32 \text { días } \\
\text { consecutivos }\end{array}$ & & \\
\hline $\begin{array}{l}\text { Protección de la } \\
\text { población local o } \\
\text { comunidad de vecinos }\end{array}$ & $\begin{array}{l}\text { Si el alquiler turístico } \\
\text { se realiza por más de } \\
2 \text { semanas al año se } \\
\text { ha de cambiar los } \\
\text { usos del suelo: la } \\
\text { vivienda pasa de uso } \\
\text { residencial a uso } \\
\text { turístico. }\end{array}$ & $\begin{array}{l}\text { Necesaria la autorización } \\
\text { de la comunidad de } \\
\text { propietarios. }\end{array}$ & & \\
\hline Seguridad/Inspecciones & $\begin{array}{l}\text { Cumplimiento } \\
\text { normativa contra } \\
\text { incendios y } \\
\text { accesibilidad para } \\
\text { discapacitados }\end{array}$ & $\begin{array}{l}\text { Cumplimiento normativa } \\
\text { contra incendios }\end{array}$ & $\begin{array}{l}\text { Cumplimiento } \\
\text { normativa contra } \\
\text { incendios }\end{array}$ & $\begin{array}{l}\text { Cumplimiento } \\
\text { normativa contra } \\
\text { incendios }\end{array}$ \\
\hline Sanciones & $\begin{array}{l}25.000 € \text { si no se tiene } \\
\text { autorización }\end{array}$ & & $\begin{array}{l}\text { Entre } 250 € \text { y } 25.000 € \\
\text { por incumplimiento de } \\
\text { normativa }\end{array}$ & $\begin{array}{l}5.000 €-10.000 € \\
\text { de multa si se } \\
\text { ejerce la } \\
\text { actividad sin } \\
\text { autorización. } \\
\text { Cierre y } \\
\text { denuncia penal } \\
\text { si no se cumple } \\
\text { con normativa } \\
\text { contra incendios }\end{array}$ \\
\hline
\end{tabular}

Cuadro 4: Síntesis de la normativa internacional: Europa

Fuente: Elaboración propia a partir de Exceltur (2015)

\subsection{Análisis del discurso: los agentes turísticos}

Tras el análisis de toda la información codificada y la extracción de la misma a través de las diferentes funcionalidades del software (Figuras 5 y 6 ), se pueden presentar los resultados del análisis del conflicto planteado.

\footnotetext{
${ }^{8}$ Pueden consultarse las preguntas y respuestas del proceso de participación pública en: https://www.cnmc.es/eses/promoci\%C3\%B3n/informesyestudiossectoriales/estudiodeeconom\%C3\%ADacolaborativa.aspx

${ }^{9}$ Decreto 28/2016, de 2 de febrero, de las viviendas con fines turísticos y de modificación del Decreto 194/2010, de 20 de abril, de establecimientos de apartamentos turísticos. http://www.juntadeandalucia.es/boja/2016/28/6
} 


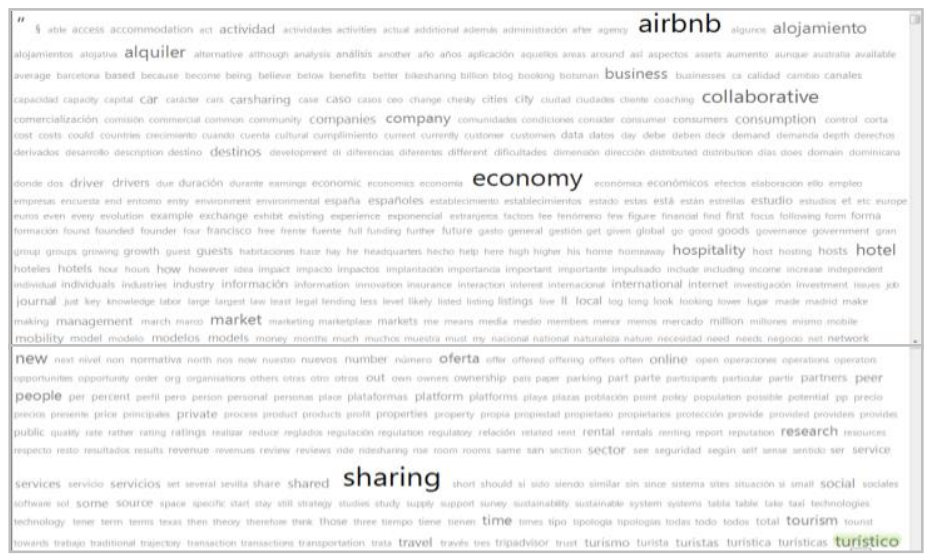

Figura 5: Nube de palabras de la bibliografía consultada

Fuente: Extraído del proceso de análisis (Atlas.ti)

Se evidencia el claro descontento de los agentes turísticos con la actividad de las plataformas P2P, principalmente por el vacío legal en el que operan, exentos de obligaciones cómo a las que tienen que hacer frente los hoteleros. No pagan los impuestos a los que están sometidos los alojamientos reglados y, sin embargo, se benefician de una demanda a la que los hoteles no pueden satisfacer, aquella que busca precios más baratos. Son tarifas a las que los hoteleros no pueden ajustarse, debido a los altos costes asociados a su actividad.

Consideran que si los alojamientos P2P estuvieran en las mismas condiciones regulatorias que la oferta reglada, les sería imposible mantener los precios tan bajos y acabarían equiparándose a la de los hoteles, causando el descenso de la actividad de las P2P. Sobre todo, porque la mayoría de arrendadores en estas plataformas son arrendadores particulares que muy probablemente no podrían hacer frente al coste de la actividad una vez regulado. Asimismo, consideran que cada vez hay más intereses empresariales tras esta actividad y son inmobiliarias, bancos y otras empresas, las que se dedican profesionalmente al alquiler P2P de viviendas vacías.

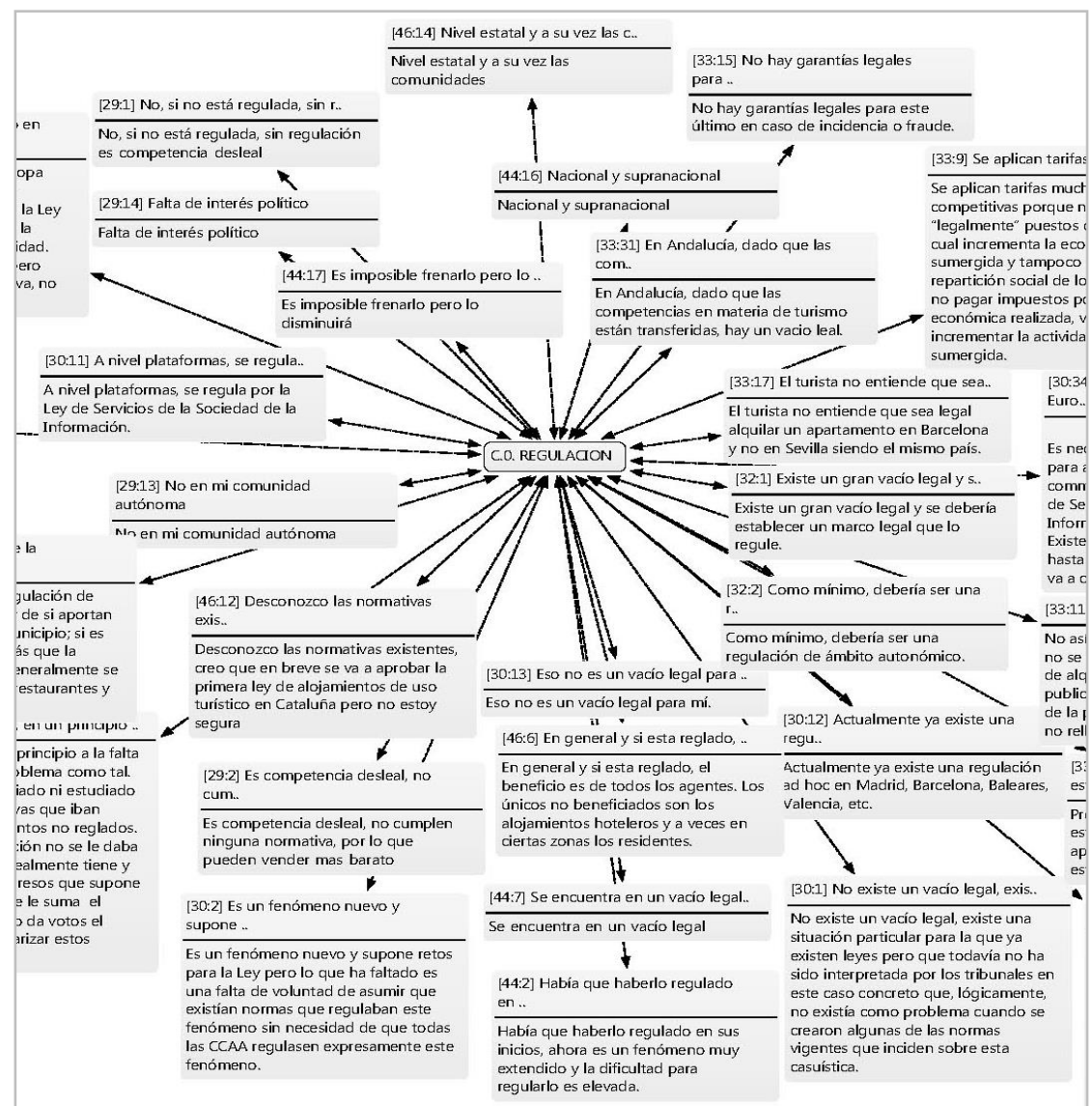

Figura 6: Sección de la red Relación de citas asociadas al código "Regulación" Fuente: Extraído del proceso de análisis (Atlas.ti) 
Por otro lado, creen que este vacío legal en el que operan las plataformas P2P se debe a la falta de atención que ha supuesto esta actividad hasta el momento, y la falta de interés por parte de las administraciones públicas.

La opinión en cuanto a las causas y factores que han propiciado la aparición de esta tipología de alojamiento y su rápida expansión en el mercado, son algo más diversas, pero la mayoría considera que la crisis económica mundial ha creado una necesidad de generar fuentes de ingresos complementarias para las familias y nuevos perfiles de demanda más influenciados por la relación entre comodidad y precio (Figura 7).

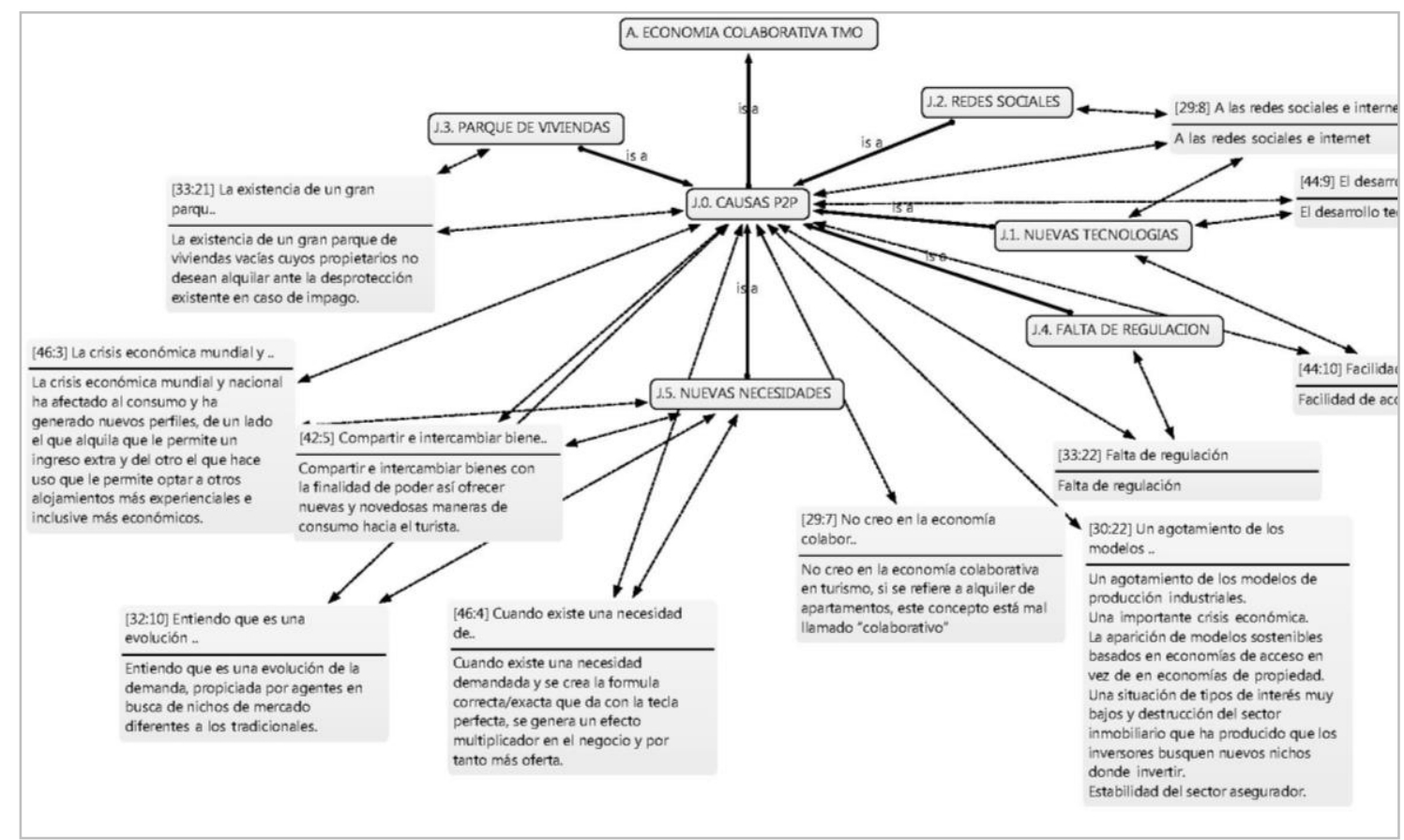

Figura 7: Red Relación de citas asociadas al código "Causas P2P" Fuente: Extraído del proceso de análisis (Atlas.ti)

En cuanto a la demanda que hace uso de los alojamientos P2P, los agentes turísticos no tienen muy claro si se trata de la misma demanda que también hace uso de los servicios regulados o, por el contrario, si se trata de una nueva demanda. Por otro lado, sí están convencidos de que la demanda usuaria de alojamientos P2P está caracterizada por el elevado uso que hacen de las nuevas tecnologías. Por la tanto, determinan que se trata principalmente de jóvenes asiduos a las compras en internet a través de dispositivos móviles y que hacen uso habitual de las redes sociales.

Finalmente, los agentes turísticos creen que el único beneficio que tiene esta actividad es el ingreso de rentas de los arrendadores particulares y las comisiones que reciben las plataformas (Figura 8). No creen que las ECS en turismo supongan ningún beneficio para el destino, ni para la economía local ni para su población, y mucho menos para las empresas y otros agentes de la oferta reglada. Consideran que se trata de una economía sumergida, que no paga impuestos y que no crea empleos. Por tanto, los únicos beneficiados de esta actividad son los arrendadores y las plataformas P2P.

\begin{tabular}{|c|c|c|c|}
\hline CÓDIGOS & $\begin{array}{c}\text { ENTREVISTAS } \\
\text { AGENTES }\end{array}$ & $\begin{array}{l}\text { ENTREVISTAS } \\
\text { USUARIOS }\end{array}$ & TOTALES: \\
\hline D.9. BANCOS & 3 & 0 & 3 \\
\hline D.10. OTRAS EMPRESAS & 3 & 1 & 4 \\
\hline E.1. GASTO & 0 & 5 & 5 \\
\hline E.2. BENEFICIO & 11 & 11 & 22 \\
\hline E.3. EXENCION IMPUESTOS & 3 & 3 & 6 \\
\hline E.4. IMPACTO NEGATIVO & 10 & 2 & 12 \\
\hline E.5. FUENTE DE INGRESO/B० ECONOMICO & 22 & 0 & 22 \\
\hline E.6. INCREMENTO DE LA ACTIVIDAD & 0 & 1 & 1 \\
\hline E.8. ANEITRIÓN_OK & 0 & 13 & 13 \\
\hline E.9. ANFITRIÓN MAL & 0 & 7 & 7 \\
\hline E.10. EMPLEO & 1 & 6 & 7 \\
\hline G.O. MOTIVACIONES USUARIOS & 6 & 6 & 12 \\
\hline G.1. PRECIO & 9 & 20 & 29 \\
\hline G.2. UBICACIÓN & 1 & 12 & 13 \\
\hline G.3. COMODIDAD & 2 & 8 & 10 \\
\hline G.4. CALIDAD & 0 & 1 & 1 \\
\hline G.5. APARIENCIA & 0 & 11 & 11 \\
\hline G.6. VALORACIONES USUARIOS & 0 & 7 & 7 \\
\hline G.7. ESPACIO & 1 & 3 & 4 \\
\hline G.8. EXPERIENCIA & 3 & 3 & 6 \\
\hline H.0. PEREIL & 7 & 0 & 7 \\
\hline
\end{tabular}

Figura 8: Densidad de códigos en cada perfil entrevistado Fuente: Extraído del proceso de análisis (Atlas.ti) 


\subsection{Análisis del discurso: los usuarios}

En cuanto al análisis del discurso de los usuarios de alojamientos P2P se puede extraer información del uso que hacen de esta tipología de viviendas, las motivaciones que les hace escoger esta opción en vez de oferta reglada, los aspectos que influyen en la decisión de escoger una vivienda anunciada frente a otra, y los beneficios que aporta esta actividad.

A través de la codificación de los discursos de los usuarios P2P ha resultado muy rápido extraer la información buscada haciendo del análisis de las motivaciones un proceso muy ágil. A continuación, se muestra la red (network) con las citas asociadas al código "Motivaciones de usuarios" y los códigos asociados al perfil (Figuras 9 y 10).

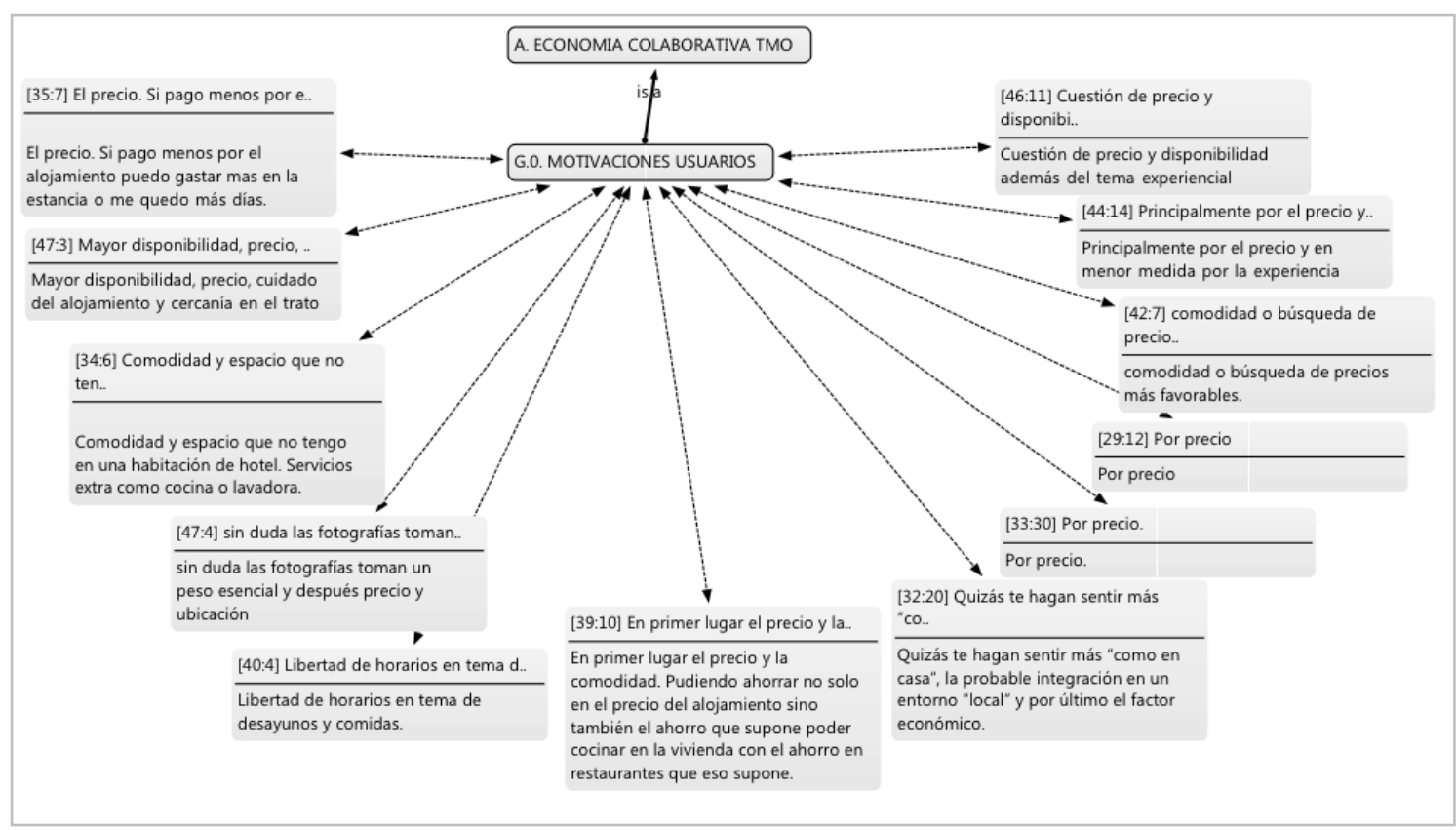

Figura 9: Red de citas asociadas al código "Motivaciones de usuarios" Fuente: Extraído del proceso de análisis (Atlas.ti)

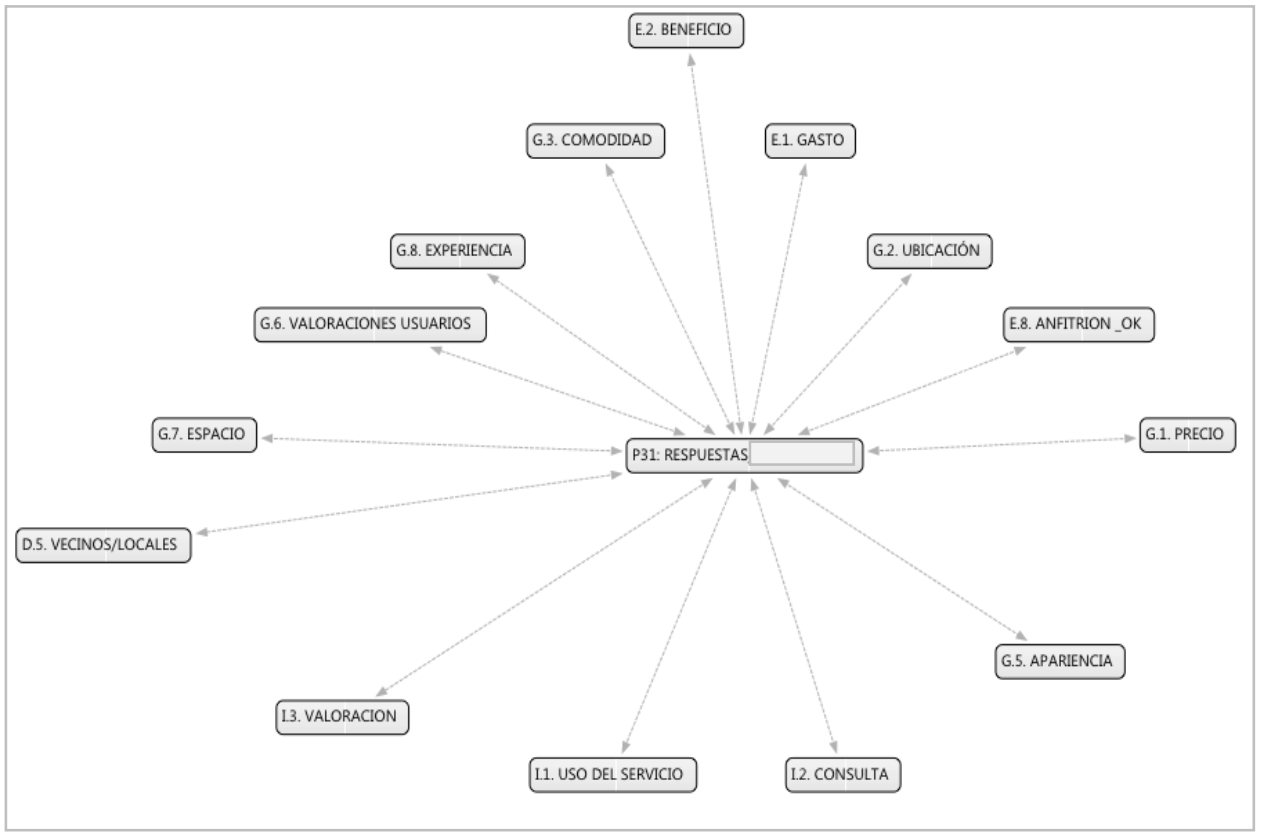

Figura 10: Red Relación de códigos asociados al perfil de un usuario P2P Fuente: Extraído del proceso de análisis (Atlas.ti) 
De este modo, podemos afirmar que el precio y la comodidad (el sentirse como en casa) son los 2 factores determinantes que hacen que un turista prefiera alojarse en una vivienda P2P en vez de un establecimiento reglado. Asimismo, otros factores como la duración de la estancia y la experiencia más local influyen en su decisión de compra.

Generalmente, el usuario P2P se aloja en esta tipología de viviendas entre una y dos veces al año, coincidiendo con los periodos vacacionales. Repiten cuando tienen ocasión pues consideran que con los precios de los alojamientos P2P se pueden permitir alquilar más veces o ampliar su estancia. Además, el dinero que se ahorran de la diferencia de los precios de las P2P con los precios de los hoteles les permite hacer un mayor gasto en el destino, ya sea en restauración o comprando en establecimientos locales.

De esta manera, consideran que esta tipología de alojamiento es beneficiosa para la economía local y para la sociedad por varios motivos: contribuyen en empresas locales, generan una fuente de ingresos para el arrendador particular y se crean una relación más cercana con la población local (partiendo del anfitrión).

A la hora de alojarse en viviendas P2P, los turistas suelen consultar como mínimo tres plataformas de anunciantes antes de contratar los servicios. El escoger una vivienda frente a otra viene determinado, principalmente, por el precio, la ubicación, la apariencia del alojamiento (fotografías) y las valoraciones de otros usuarios. El binomio precio-ubicación prima en la decisión de la persona, pero este factor se complementa necesariamente con los otros aspectos.

Hay que tener en cuenta que los comentarios de otros huéspedes sobre una vivienda influyen, en gran medida, a potenciales usuarios. En muchos casos, cuando una vivienda gusta por su precio y apariencia, el que exista un comentario negativo respecto al anfitrión o al alojamiento va a determinar la formalización de la operación. La reputación del arrendador y de su anuncio es fundamental para crear un vínculo de confianza con posibles usuarios, pues frente a los sistemas homologados de calidad de los hoteles, las valoraciones de los huéspedes es el único mecanismo de "certificación".

\subsection{Análisis del discurso: el conflicto}

Finalmente, se puede concluir que la base principal sobre la que se asienta el conflicto entre la oferta reglada y la no reglada es la falta de regulación turística de este fenómeno. Las empresas P2P no se oponen a que se les aplique normativas relativas al servicio de alojamiento que prestan sus anfitriones, sin embargo, se ha de realizar una normativa acorde a la dimensión de la tipología de alojamiento que presentan y teniendo en cuenta que no se trata de una actividad profesional como la realizada por hoteles, sino que generalmente, se trata de arrendadores individuales en busca de una renta complementaria.

Por otro lado, es posible que una vez elaborada la normativa aplicable, haya descontentos del sector del alojamiento por el contenido de la misma. Podrá deberse a que a este sector no le agrade el grado de exigencia del contenido o que, al tratarse de una competencia autonómica, la desigualdad entre regulaciones sea el nuevo foco del conflicto.

Parece ser que, en parte, el objetivo de la oferta reglada en la exigencia de la regulación de las plataformas P2P no sea solucionar el vacío legal en el que éstas operan y eliminar la competencia desleal que supone su actividad. Parece ser que, al controlar la actividad por ley y al acarrearles una serie de gastos e inversiones para cumplir con la normativa, se verán obligados a elevar los precios, asemejándose a los de la oferta reglada y derivando en un continuo freno de su actividad, el descenso de la misma o, incluso, su desaparición en el mercado del alojamiento.

Mientras los legisladores se ponen de acuerdo en los ámbitos regulatorios de aplicación a la oferta P2P, al sector hotelero no le queda más opción que seguir desarrollando su actividad como hasta el momento y convivir con este nuevo fenómeno que está continuamente revolucionando el sector turístico.

\section{CONCLUSIONES Y PERSPECTIVAS DE INVESTIGACIÓN}

\subsection{Conclusiones}

Las economías colaborativas en el turismo, específicamente en el segmento del alojamiento, es un tema que, tanto por su carácter reciente como por la naturaleza de la oferta (fuera de registros oficiales) no ha sido afinado desde el punto de vista cuantitativo. La mayor parte de la información al respecto es cualitativa y se basa en opiniones, actitudes, sentimientos, motivaciones y explicaciones a problemas. La controversia del asunto, con diversos agentes o posicionamientos, complejiza y enriquece el debate. Desde el punto de vista metodológico, el uso de la herramienta del análisis del discurso ha sido eficaz para sintetizar, ordenar y confrontar la información sobre un tema amplio, reciente y controvertido.

Los negocios P2P ofrecen mayor flexibilidad para que el oferente y el demandante puedan acordar términos que se acoplen a las necesidades de ambos: acordar un horario y lugar de salida del viaje, alojarse en una vivienda en un periodo en el que el propietario no la está usando o conocer un destino a través de la experiencia de un residente. Esa flexibilidad está íntimamente relacionada con las nuevas tecnologías, las nuevas formas de 
consumo online y las redes sociales como nuevo mecanismo de comunicación e información. Bajo este contexto, en el área del alojamiento, parece ser que existe una creciente demanda que prefiere gastar menos en alojamiento para disfrutar mejor y más tiempo del destino, personas que buscan espacios que les haga sentir como en casa, pero a su vez, más integrados en el lugar y la cultura local. Y es que estas fórmulas P2P han sido un éxito viendo la gran expansión que han tenido en los últimos años y la aceptación que han tenido por parte de sus usuarios.

Los agentes hoteleros, ante el rápido crecimiento de estas fórmulas alternativas de alojamiento, están descontentos y las consideran una competencia desleal. Las plataformas que comercializan esta nueva oferta operan bajo normativas del ámbito del comercio electrónico y, de esa forma, evaden el pago de una serie de impuestos e inversiones para ajustarse a las regulaciones propias del sector. Este hecho, junto con otros factores, les permite aplicar tarifas reducidas respecto a los precios de la oferta regulada. Consideran que si operaran bajo las mismas obligaciones que el resto del sector no podrían seguir manteniendo esos precios, acabarían equiparándose con las tarifas hoteleras, perderían gran parte de su demanda y, en definitiva, sufrirían un descenso en su actividad.

El malestar de alojamientos y asociaciones hoteleras se agrava sabiendo que las P2P llevan años operando en el mercado pero que, no ha sido hasta principios de 2014 cuando comienza a hacerse patente un interés desde las instituciones públicas competentes. La tardanza en establecer una normativa y la falta de homogeneidad a nivel nacional de unas bases reguladoras, sigue manteniendo una actitud de rechazo por parte del sector hotelero a este fenómeno.

El estudio de la normativa internacional y nacional refleja el intento de apaciguar el conflicto al establecer ciertas bases en función de las características propias de los alojamientos y plataformas P2P, intentando abarcar ámbitos normativos propios de la oferta reglada. Aunque los ítems a regular suelen ser los mismos (habitualidad, dotaciones mínimas, seguridad, zonificación y población local), la disparidad entre las normas analizadas ha quedado patente.

Del análisis del discurso se extrae que la percepción del beneficio es distinta según los perfiles entrevistados (beneficio del destino, de los arrendadores y sus familias, de las grandes y medianas empresas hoteleras). Según los agentes hoteleros, su actividad genera un beneficio colectivo indirecto más amplio a través de su contribución a las arcas públicas (impuestos) y la generación de más empleo (directo e indirecto) entre la población local. Desde el punto de vista de los usuarios P2P son los propios turistas los que se encargan de redistribuir el beneficio: dentro del propio destino (ampliando la estancia o gastando en otros negocios) o en otros destinos (invirtiendo lo ahorrado en la estancia en un nuevo viaje). A ello suman el beneficio de carácter social o cultural que resulta de la mayor interacción entre el viajero y la comunidad local.

\subsection{Perspectivas de investigación}

La presente línea de investigación deberá explorar en un futuro próximo nuevas normativas o documentos de referencia, así como la opinión de otros agentes implicados (plataformas, arrendadores y comunidades de vecinos). Asimismo, este trabajo puede ser el punto de partida del que podrían nacer los siguientes temas de estudio:

- Impacto de la aplicación normativa en las P2P. Algunos destinos internacionales están siendo los pioneros en la regularización de la actividad de las plataformas de ECs Son numerosos los destinos en los que se trabaja por normalizar la actividad P2P, pero el impacto que está generando la aplicación de las normativas, o si se están cumpliendo, se desconoce en profundidad. Como se ha hecho referencia, la Junta de Andalucía aprueba su Decreto sobre viviendas de uso turístico (Decreto 28/2016) y su análisis pormenorizado podría complementar la presente investigación.

- La demanda P2P: ¿nueva demanda o la misma con nuevas necesidades? No son claras las conclusiones sobre cuál es el perfil del usuario P2P. No hay un claro consenso al respecto, por lo que el estudio sobre el perfil actual del usuario de los servicios de ECs puede ser otra posible línea de investigación.

Distribución e impacto de la actividad P2P en el espacio urbano. La oferta reglada afirma que los alojamientos P2P se ubican en los barrios más céntricos y turísticos mientras que los establecimientos hoteleros se reparten de manera más equitativa por los diferentes distritos urbanos $y$, por tanto, hay una mayor redistribución de los beneficios de su actividad. Por otro lado, Airbnb afirmaba en su estudio realizado para la ciudad de Madrid, que el $70 \%$ de sus anunciantes se encontraban fuera del Centro (Airbnb, 2015). Asimismo, en algunas normativas internacionales se regula la actividad P2P a través de la zonificación, evitando la concentración de estas viviendas en los barrios más turísticos. Los anuncios publicados en las plataformas P2P podrían geolocalizarse y analizarse -a través de un software SIGrelacionando la distribución de la planta alojativa P2P con la dinámica turística del destino y con los indicadores económicos y sociales de cada sector de la ciudad. 


\section{BIBLIOGRAFÍA}

Airbnb (2015). El Impacto del alojamiento compartido en Madrid. Recuperado de http://www.thinktur.org/media/Airbnb Estudio impacto econymico en Madrid.pdf

Allen, D. \& Berg, C. (2014). The Sharing Economy: How over-Regulation Could Destroy an Economic Revolution. Institute of Public Affairs. Recuperado de https://ipa.org.au/publications/2312/the-sharing-economy-howover-regulation-could-destroy-an-economic-revolution.

Belk, R. (2014). You Are What You Can Access: Sharing and Collaborative Consumption Online. Journal of Business Research Vol.67 (8), (1595-1600).

Botsman, R. (2013). The Sharing Economy lacks a shared definition. Fast Company. Recuperado de http://www.fastcoexist.com/3022028/the-sharing-economy-lacks-a-shared-definition\#1

Botsman, R. \& Rogers R. (2011). What's mine is yours: How collaborative consumption is changing the way we live. London: Harper Collins Business.

Cohen, B. \& Kietzmann, J. (2014). Ride On! Mobility Business Models for the Sharing Economy. Organization and Environment Vol. 27 (3), 279-296.

CEHAT (Confederación Española de Hoteles y Apartamentos Turísticos) (2013). Identificación de mejores prácticas internacionales en la regulación de la oferta de vivienda particular para uso turístico. Madrid: CEHAT.

De la Calle, A. \& De la Calle, P. (2013). The Collaborative Consumption: a form of consumption adapted to modern times. Revista de Estudios Económicos y Empresariales, 25, 15-30. Recuperado de http://dehesa.unex.es:8080/xmlui/bitstream/handle/10662/1291/0212-7237 25 15.pdf?sequence=1

Decreto 18/2016 de las viviendas con fines turísticos y de modificación del Decreto 194/2010, de 20 de abril, de establecimientos de apartamentos turísticos. Boletín Oficial de la Junta de Andalucía, 11 de febrero de 2016.

Exceltur (2015). Alojamiento turístico en viviendas de alquiler: impactos y retos asociados. Madrid: Exceltur. Recuperado de http://www.exceltur.org/monograficos/alojamiento-turistico/.

Freese, C. \& Schönberg, A. T. (2014). Shared mobility: how new businesses are rewriting the rules of the private transportation game. Think Act. Recuperado de http://www.rolandberger.com/media/pdf/Roland Berger TAB Shared Mobility 20140716.pdf

Gansky, L. (2010). The Mesh: Why the Future of Business is Sharing. New York, NY: Portfolio Penguin.

Lamberton, C. P. \& Rose, R. L. (2012). When ours is better than mine? A framework for understanding and altering participation in commercial sharing systems. Journal of Marketing 76(4), 109-125.

Ley 29/1994 de Arrendamientos Urbanos. Boletín Oficial de Estado, España, 25 de noviembre de 1994.

Ley 4/2013 de medidas de flexibilización y fomento del mercado del alquiler de viviendas. Boletín Oficial del Estado, España, 5 de junio de 2013.

Olsen, M. \& Kemp, S. (2015). Sharing economy: an in-depth look at its evolution and trajectory across industries. Piper Jaffray Investment Research. Marzo 2015. Recuperado de http://collaborativeeconomy.com/wp/wp-content/uploads/2015/04/Sharing-Economy-An-In-Depth-LookAt-Its-Evolution-and-Trajectory-Across-Industries-.pdf .

Román, A. (2014). Las viviendas particulares dedicadas a la actividad de alojamiento turístico. Su exclusión de la Ley de Arrendamientos Urbanos. Revista Internacional de Doctrina y Jurisprudencia, volumen 6.

Sacks, D. (2011). The sharing economy. Fast Company. Recuperado de http://www.fastcompany.com/1747551/sharing-economy .

Stokes, K., Clarence, E., Anderson, L. \& Rinne, A. (2014). Making Sense of the UK Collaborative Economy. London: Nesta. Recuperado de http://collaborativeeconomy.com/research/making-sense-of-the-ukcollaborative-economy/

Tussyadiah, I.P. (2015). "An Exploratory Study on Drivers and Deterrents of Collaborative Consumption in Travel”. En I. Tussyadiah \& A. Inversini (eds.), Information \& Communication Technologies in Tourism. Lugano: Springer International Publishing, 817-830. 